\title{
ANÁLISE ERGONÔMICA DO TRABALHO DE UM AUXILIAR DE ATENDIMENTO COM DEFICIÊNCIA MOTORA
}

\section{ERGONOMIC ANALYSIS OF WORK OF AN ATTENDANT WITH MOTOR DEFICIENCY}

\author{
Marina Macedo Poleza Castanho', Arq. \\ Marina Bernardes ${ }^{2}$, Arq. \\ Leila Gontijo ${ }^{3}$, Dra. \\ Lizandra Lupi Vergara ${ }^{\mathfrak{f}}$, Dra.
}

(1) Universidade Federal de Santa Catarina e-mail: marinapoleza@gmail.com

(2) Universidade Federal de Santa Catarina e-mail: arq.marinabernardes@gmail.com

(3) Universidade Federal de Santa Catarina e-mail: leila.gontijo@ufsc.br

(4) Universidade Federal de Santa Catarina e-mail: lizandravergara@gmail.com

Ergonomia, deficiência, Análise Ergonômica do Trabalho.

Este artigo apresenta uma Análise Ergonômica do Trabalho (AET) de um funcionário com deficiência motora em um ambiente farmacêutico. Foram realizadas: entrevistas, levantamento fotográfico, medições e acompanhamento de atividades. Os resultados evidenciam que a farmácia em estudo precisará tomar diversas providencias e adaptarse a uma série de leis e normatizações de acessibilidade.

Ergonomics, deficiency, Ergonomic Work Analysis

This article presents an Ergonomic Analysis of the Work of an employee with motor deficiency in a pharmaceutical environment. We conducted interviews, photographic survey, mesuraments and activities monitoring. Results shows that the studied drugstore needs several improvements, adapting to laws and accessibility norms. 


\section{$16^{\circ}$ \\ ERGODESIGN USIHC CINAHPA}

\section{Introdução}

De acordo com a Organização Mundial de Saúde (OMS) mais de 1 bilhão de pessoas no mundo possuem algum tipo de deficiência, sendo temporária ou permanente, todas as pessoas em algum momento de suas vidas enfrentarão dificuldades. (OMS, 2011). Segundo dados do Instituto Brasileiro de Geografia e Estatística (IBGE), 17,7 milhões de brasileiros possuem algum tipo de deficiência grave, sendo que deste total 2,3\% da população é composta por deficientes motores (IBGE, 2010). Somado aos portadores de deficiência permanente, encontram-se aqueles que apresentam limitações temporárias, como: grávidas, mães com bebes com carrinhos e aqueles que passaram por cirurgias ou encontram-se com algum membro mobilizado. (DUARTE E COHEN, 2003). No Brasil, a Legislação 8213/91, obriga as empresas públicas e privadas a contratar pessoas com deficiência. (BRASIL, 1991).

Freitas (2009) afirma que estudos sobre a gestão da diversidade, focado nas pessoas com deficiência, tem apresentado três grandes dificuldades: a primeira está no fato de como os gestores veem a deficiência, a segunda está na adequação das condições e práticas do trabalho da empresa e a terceira em conseguir avaliar a satisfação dos empregados com deficiência no ambiente de trabalho. Nesse contexto, a Ergonomia surge como aliada, pois o ergonomista que estuda a relação entre o homem e seu trabalho, pode identificar, analisar, diagnosticar e corrigir situações nos postos de trabalhos visando uma relação mais produtiva e eficiente. (IIDA, 2005)

Este artigo analisa ergonomicamente um posto de trabalho em uma farmácia (aqui denominada Farmácia Y), ocupado por um auxiliar com deficiência motora (aqui denominado funcionário $\mathrm{X}$ ), onde será utilizado um conjunto de métodos e técnicas em ergonomia com a perspectiva de avaliar os problemas enfrentados por esse funcionário e de alguma forma contribuir e estimular novos estudos. A deficiência é contemplada em perspectiva restrita, com foco na deficiência motora apresentada pelo Funcionário. $16^{\circ}$ Ergodesign - Congresso Internacional de Ergonomia e Usabilidade de Interfaces Humano Tecnológica: Produto, Informações Ambientes Construídos e Transporte

$16^{\circ}$ USIHC - Congresso Internacional de Ergonomia e Usabilidade de Interfaces Humano Computador

CINAHPA | 2017 - Congresso Internacional de Ambientes Hipermídia para Aprendizagem.

\section{Referencial teórico}

A Lei Brasileira número 13. 146/2015 de Inclusão da Pessoa com deficiência no ambiente de trabalho visa "assegurar e promover, em condições de igualdade, o exercício dos direitos e das liberdades fundamentais por pessoa com deficiência, visando à sua inclusão social e cidadania". O Art. 34 desta lei garante que "a pessoa com deficiência tem direito ao trabalho de sua livre escolha e aceitação, em ambiente acessível e inclusivo, em igualdade de oportunidades com as demais pessoas". (BRASIL, 2015). A NBR 9050, elaborada pela Associação Brasileira de Normas Técnicas (ABNT), orienta arquitetos e engenheiros no que diz respeito ao processo de implantação de diretrizes de acessibilidade, para edificações, mobiliário e equipamentos urbanos. (NBR 9050, 2015).

De acordo com a OMS a participação de pessoas com deficiência na força de trabalho é importante pelas seguintes razões: Maximizar os recursos humanos; Promover a dignidade humana e a coesão social; Acomodar os números crescentes de pessoas com deficiência na população em idade produtiva. (OMS, 2011). A Ergonomia com seus métodos flexíveis de Análise Ergonômica do Trabalho (AET), com ferramentas variadas para coletas de dados, escolhidas de acordo com o objetivo definido pela Demanda.

Neste artigo a Análise da Demanda descreverá uma situação problemática que justifique a Análise Ergonômica do posto de trabalho. Na Análise da Demanda propõe-se formalizar os diversos conhecimentos, compreender problemas relacionados aos operadores, criar pontos de partidas para as fases seguintes, analisar e avaliar a magnitude dos problemas levantados e, por fim, identificar diversas soluções para os problemas (ABRAHÃO et al., 2009).

Na Análise da Tarefa serão avaliadas as condições prescritas do trabalho. Já na Análise das Atividades será avaliado o comportamento do Funcionário X no posto de trabalho. No Diagnostico são apresentadas às causas que provocam os problemas descritos na demanda e nas Recomendações serão
Realização:

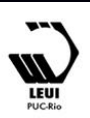




\section{$16^{\circ}$ \\ ERGODESIGN USIHC CINAHPA}

apresentadas as soluções para os problemas descritos no Diagnostico. As Recomendações visam auxiliar na concepção das transformações no trabalho (ABRAHÃO et al., 2009).

\section{Procedimentos Metodológicos}

Este trabalho é uma pesquisa exploratória e qualitativa, caracterizada como um estudo de caso. Foi realizado por meio da observação direta das atividades do ambiente estudado (GIL, 2010). Os procedimentos metodológicos adotados na pesquisa foram estruturados em cinco etapas:

Demanda: Entrevista não estruturada com os funcionários e gerente da farmácia para reconhecimento da problemática; Informações sobre a empresa. Tarefa: Levantamento documental; Levantamento métrico e fotográfico; Esclarecimentos sobre o funcionamento da empresa, Objetivo do trabalho, Levantamento de máquinas e ferramentas, Meio ambiente, Organização e Exigências do trabalho. Análise da Atividade: Observação do funcionário em seu posto de trabalho; Interações; Entrevistas; Registros fotográficos. Diagnóstico, propondo recomendações.

\section{Resultados e discussão}

\subsection{Análise da Demanda}

A Farmácia Y está inserida na maior rede de farmácias da região sul do Brasil e possuí um programa de inclusão para Pessoas com deficiência (PcD) que objetiva oportunizar a inserção dessas pessoas no mercado de trabalho, desenvolver suas potencialidades e habilidades e auxiliá-los na ampliação de suas qualificações profissionais. A Demanda deste trabalho surge com a intenção de identificar quais são as características que uma situação de trabalho em uma farmácia deverá ter para receber um funcionário com deficiência motora, considerando a insatisfação do funcionário estudado.

\subsection{Análise da tarefa}

O funcionário selecionado para este estudo, $16^{\circ}$ Ergodesign - Congresso Internacional de Ergonomia e Usabilidade de Interfaces Humano Tecnológica: Produto, Informações Ambientes Construídos e Transporte

$16^{\circ}$ USIHC - Congresso Internacional de Ergonomia e Usabilidade de Interfaces Humano Computador

CINAHPA | 2017 - Congresso Internacional de Ambientes Hipermídia para Aprendizagem. apresenta deficiência motora na mão direita, que limita movimentos que envolvem força e agilidade, atua como auxiliar de atendimento, tem 40 anos de idade, 1,68 de altura e possui o segundo grau completo. Ele é o primeiro funcionário com deficiência a trabalhar na Farmácia Y e não possuía experiência na área antes de ser contratado.

Cabe ao funcionário $\mathrm{X}$ realizar as seguintes tarefas prescritas pela empresa: atuar no processo de recebimento de produtos na loja, tomando as providências cabíveis quando houver alguma inconformidade; auxiliar na estocagem dos produtos conforme padrões estabelecidos, atentando para as especificidades desses produtos e seu acondicionamento, tendo como função geral, manter a organização do espaço. Para executar seu trabalho o Funcionário utiliza as seguintes ferramentas: Computadores (Instalados nos Caixas, Atendimento e Administrativo), leitor de código de barras (Instalado nos Caixas e no Atendimento), caixas para o transporte dos produtos e medicamentos e etiquetador de preços. A Farmácia possui uma área aproximada de $150 \mathrm{~m}^{2}$, composta por um setor de caixas, setor de expositores, balcão de atendimento, administração e estoque de remédios controlados que ficam no primeiro pavimento. O estoque geral, a cozinha e o vestiário ficam no segundo pavimento, o acesso é feito por uma escada metálica tipo caracol.

Mesmo inserida em programas sociais a Farmácia em estudo não apresenta nenhum tipo de treinamento no que diz respeito ao treinamento especifico de PcD. Os demais funcionários também não são treinados para receberem funcionários com deficiências e cabe a gerente a fazer o papel de intermediadora.

\subsection{Análise da atividade}

A atividade do Funcionário $\mathrm{X}$ foi analisada durante 02 dias. Elaborou-se um mapa de fluxos para maior entendimento dos percursos, os horários foram categorizados e separados por períodos, onde é possível observar os períodos de trabalho, a atividade, a localização do funcionário dentro da farmácia e o movimento de clientes. Desta forma foi possível relacionar o tempo despendido para

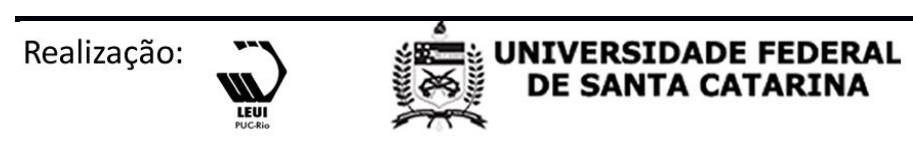




\section{$16^{\circ}$ \\ ERGODESIGN USIHC CINAHPA}

cada tarefa, o tipo da atividade solicitada pela gerente e se a quantidade de clientes interferiu na atividade do funcionário.

Analisando o tempo destinado para cada atividade constatou-se que durante o primeiro dia de análise o funcionário $X$ utilizou a maior parte do seu tempo $(57,16 \%)$ executando a atividade de organização da prateleira de higiene pessoal. Esta atividade envolveu o deslocamento intenso entre a Área de Expositores e a Área de Estoque Geral. Os objetivos principais da tarefa foram; organizar os produtos na prateleira de acordo com as regras da franquia, repor os produtos do estoque para as prateleiras, checar a quantidade dos produtos em estoque e assinalar a quantidade desses produtos no computador. O funcionário se manteve em pé, não apresentando sinais de desconforto ao realizar as atividades propostas, em contra ponto, seu descontentamento ficou evidente no uso da escada, sendo observado na seguinte fala: "essa escada é muito perigosa, tenho medo de cair, mas preciso usar né, não tenho escolha, perco muito tempo subindo e descendo".

Caixas de plástico são disponibilizadas para o funcionário carregar os produtos, mas eles são grandes e pesadas, o que dificulta ainda mais o trabalho. $\mathrm{O}$ acesso aos produtos das prateleiras altas do estoque também se mostrou crítico, "essas prateleiras de produtos são muito altas, nem uma pessoa normal consegue pegar", reclamou o funcionário. A Farmácia não possui um computador na área de estoque, desta forma, o funcionário necessita utilizar o computador da administração, localizado no piso térreo, para digitalizar os dados do estoque.

O Atendimento de clientes despendeu 28,58\% do tempo do funcionário, foi o momento de maior movimento na farmácia, o funcionário realizou vendas de medicamentos, conferiu preços com o leitor de código de barras e efetuou pagamentos. Já $14,29 \%$ do tempo do funcionário foi gasto com o horário de intervalo do almoço. $\mathrm{O}$ funcionário optou em ficar na cozinha da farmácia, aproveitou o tempo de descanso para mexer no celular e organizar objetos pessoais. $16^{\circ}$ Ergodesign - Congresso Internacional de Ergonomia e Usabilidade de Interfaces Humano Tecnológica: Produto, Informações Ambientes Construídos e Transporte

$16^{\circ}$ USIHC - Congresso Internacional de Ergonomia e Usabilidade de Interfaces Humano Computador

CINAHPA | 2017 - Congresso Internacional de Ambientes Hipermídia para Aprendizagem.
No segundo dia devido ao alto número de clientes e a folga de um de seus colegas de trabalho o funcionário gastou $71,45 \%$ do seu tempo na área do Atendimento. O Balcão de atendimento é equipado somente com 02 computadores e por muitas vezes o funcionário teve que ir até a área administrativa para buscar informações sobre algum tipo de produto ou medicamento. A área de atendimento possui um corredor de $75 \mathrm{~cm}$ e estava cheia de objetos que obstruíam a boa circulação, segundo o funcionário: "acho muito ruim esse balcões, não tem espaço para sentar, é cheio de coisas". O Funcionário X requisitou a ajuda de seus colegas em vários momentos e relatou; "as vezes eu fico um pouco perdido, não sei o nome e composição de muitos medicamentos". A dificuldade do Funcionário X ao manusear o leitor de código de barras móvel ficou evidente em várias situações. Além disso, constatou-se a falta de conforto na hora do intervalo, pois a cozinha possui um espaço restrito e com pouca estrutura. Neste dia o funcionário aproveitou o intervalo para dar uma volta no shopping e reclamou: "É complicado ficar aqui por uma hora, não tem onde sentar com conforto, prefiro sair e dar uma volta no shopping ou até mesmo sair na rua."

\section{Diagnóstico e recomendações}

O Diagnóstico e as Recomendações foram divididos em duas etapas, a primeira contendo recomendações simples, rápidas de solucionar e com um custo baixo de execução. A segunda etapa, com prazos maiores para execução e com maiores investimentos financeiros.

Na primeira etapa do Diagnóstico foram detectados problemas no manuseio do leitor do código de barras móvel, dificuldade ao transportar as grandes caixas plásticas de medicamentos entre a área de exposição e estoque geral, falta de espaço para sentar na área de atendimento e administração, assim como falta de computadores para conferencia de medicamentos, tanto na área de atendimento como do estoque geral e ausência de treinamento e conhecimento sobre os medicamentos.

Surge como recomendação para esta primeira

Realização:




\section{$16^{\circ}$ \\ ERGODESIGN USIHC CINAHPA}

etapa: Substituir os leitores de código de barra de móvel para fixo, para que todos os funcionários, independente da deficiência, tenham mais agilidade e facilidade ao manusear os produtos. As caixas grandes e pesadas de plástico poderão ser substituídas por cestos de plástico com rodas e alças, objetivando facilitar o transporte dos medicamentos. Desobstruir os espaços destinados para as cadeiras no atendimento e administração e armazenar de forma correta e em lugar adequado os objetos encontrados hoje nesses lugares.

Comprar 01 computador para a área de atendimento e 01 para o estoque geral, já que foi observado que o funcionário passa grande parte do se tempo nesses ambientes e requer constantemente o uso desses aparelhos para a consulta interna. Para finalizar esta primeira etapa a Farmácia deverá investir em palestras e treinamentos para manter os funcionários constantemente atualizados.

Em relação à altura das prateleiras sugere-se o Artigo 4.6.1 da NBR 9050 que preconiza a altura entre 1,40 a 1,55 para o alcance máximo confortável. Para tanto as prateleiras do setor de estoque e exposição deverão ser redimensionadas e suas alturas reduzidas. Os produtos retirados dessas prateleiras poderão ser facilmente distribuídos em prateleiras adicionais. Para os corredores de circulação sugere-se o artigo 6.11 que faz referência a circulação interna, onde corredores de até $4 \mathrm{~m}$ deverão ter a largura de mínima de $90 \mathrm{~cm}$ e corredores de até $10 \mathrm{~m}$ deverão ter largura mínima de $1,20 \mathrm{~m}$.

Para resolver a problemática da escada tipo caracol conclui-se que a substituição por um elevador pequeno, seria a melhor solução. O elevador poderá ser instalado no mesmo local da escada, sem a necessidade de abrir um vão maior na laje. Para melhorar as condições da cozinha e espaço de descanso dos funcionários, uma mesa mais confortável deverá ser colocada no local, para que os funcionários façam as refeições com qualidade, uma geladeira maior para o armazenamento das marmitas e uma área de estar com sofás e puffs deverá ser projetada. Para melhor compreensão, foi elaborado um layout de apresentação do Layout atual e a proposta final para o layout do primeiro e segundo pavimento (Figura 1,2,3e 4).

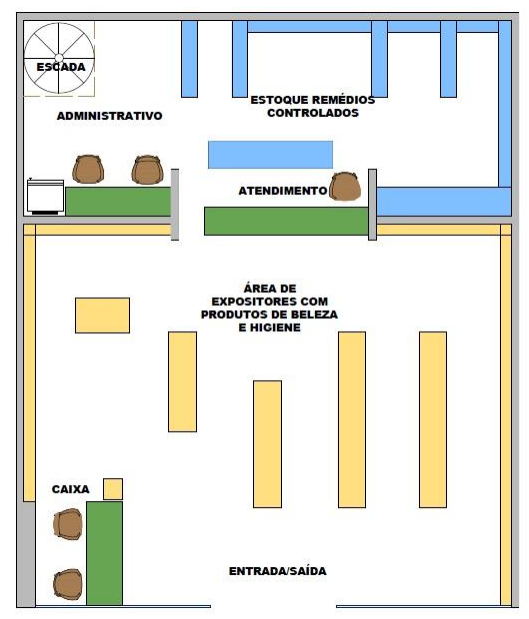

Figura 01: Layout atual, primeiro pavimento. Fonte: Autoras, 2017.

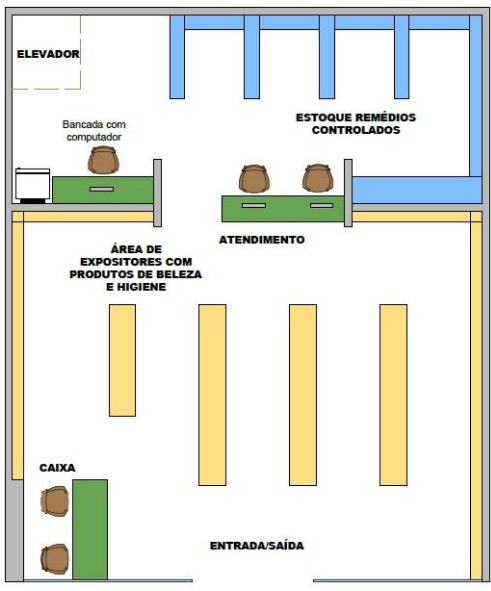

Figura 02: Proposta de novo layout, primeiro pavimento.

Fonte: Autoras, 2017.

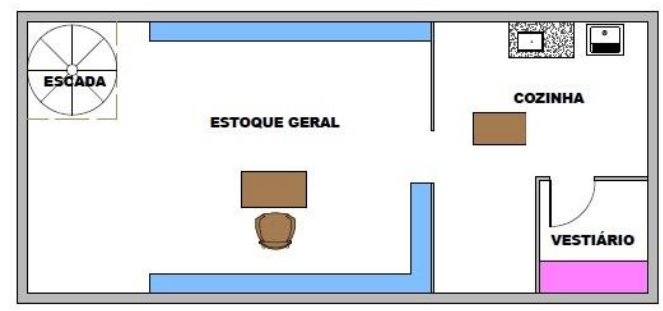

Figura 03: Layout atual, segundo pavimento. Fonte: Autoras, 2017. 


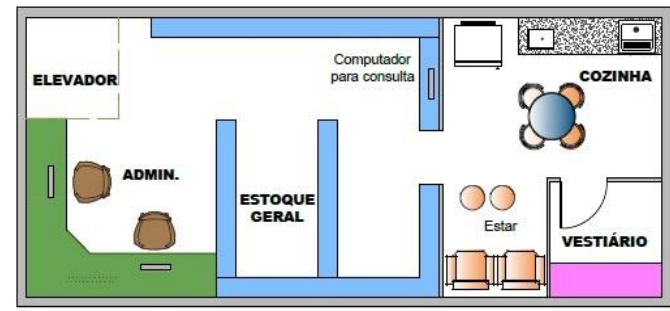

Figura 04: Proposta de novo layout, segundo pavimento.

Fonte: Autoras, 2017.

\section{Conclusão}

Observou-se ao longo deste trabalho que a deficiência apresentada pelo Funcionário X contribuiu para a detecção de muitos problemas relacionados acessibilidade. Alguns fáceis de solucionar, outros, exigirão mais investimentos e disposição. É importante salientar que para tornarse uma farmácia acessível, é necessário adaptar-se a uma série de leis e normatizações de acessibilidade, principalmente em relação ao layout do espaço e mobiliário. Salientando que neste trabalho foram diagnosticadas somente as demandas apresentadas no posto de trabalho do Funcionário X. Consequentemente, faz-se necessário que sejam realizadas pesquisas adicionais de forma a aumentar o entendimento sobre as características que uma situação de trabalho em uma farmácia deverá ter para receber um funcionário com deficiência motora. Ressaltase que as deficiências podem apresentar-se de inúmeras formas e cada funcionário portador de deficiência deverá receber atenção especial em seu posto de trabalho, para que ele possa desenvolver sua função de uma forma correta, eficiente e digna. $16^{\circ}$ Ergodesign - Congresso Internacional de Ergonomia e Usabilidade de Interfaces Humano Tecnológica: Produto, Informações Ambientes Construídos e Transporte

$16^{\circ}$ USIHC - Congresso Internacional de Ergonomia e Usabilidade de Interfaces Humano Computador

CINAHPA | 2017 - Congresso Internacional de Ambientes Hipermídia para Aprendizagem.
BRASIL. Lei n. 13.146. Inclusão da Pessoa com Deficiência (Estatuto da Pessoa com Deficiência), 2015

BRASIL. Lei n. 8.213. Dispõe sobre os Planos de Benefícios da Previdência Social e dá outras providências. Brasília: DOU, 1991a.

DUARTE, C.R. e COHEN, R. (coord) Acessibilidade para todos, uma cartilha de orientação. Rio de Janeiro: Núcleo Pró-Acesso, UFRJ/FAU/PROARQ, 2004.

FREITAS, M. N. C. Inserção e Gestão do Trabalho de Pessoas com Deficiência: um Estudo de Caso. Curitiba 2009

GIL, A.C. Como elaborar projetos de pesquisa.

São Paulo. $5^{\circ}$ Ed. Editora: Atlas. 2010.

IBGE (Instituto Brasileiro de Geografia e Estatística) CENSO DEMOGRÁFICO 2010. Disponível em:

ftp://ftp.ibge.gov.br/Censos/Censo_Demografico_2 010/Caracteristicas_Gerais_Religiao_Deficiencia/c aracteristi cas_religiao_deficiencia.pdf. Acesso em 18 de outubro de 2016

IIDA, I. Ergonomia projeto e produção. 2. ed. São Paulo: Edgard Blucher, 2005.

OMS, Organização Mundial da Saúde, http:// http://www.pessoacomdeficiencia.sp.gov.br/usr/sha re/documents/RELATORIO_MUNDIAL_COMPL ETO. Acessado em 13 de out 2016 . .

\section{BIBLIOGRAFIA}

ABRAHÃO, J.; SZNELWAR, L.; SILVINO, A.; SARMET, M.; PINHO, D. Introdução à ergonomia: da prática à teoria. São Paulo, Blucher, 2009.

ASSOCIAÇÃO BRASILEIRA DE NORMAS TÉCNICAS. NBR 9050: Acessibilidade a edifcações, mobiliário, espaços e equipamentos urbanos. Rio de Janeiro: ABNT, 2015. 